\title{
SICAKLIK VERİLERİNİN TREND ANALİŻ̇: ÇANKIRI VE KASTAMONU ÖRNEĞİ
}

\author{
Ahmet İLKER ${ }^{*}$, Özlem TERZí ${ }^{2}$ \\ 1 Çankırı Karatekin Üniversitesi, Meslek Yüksekokulu, İnşaat Bölümü, Çankırı, Türkiye \\ ${ }^{2}$ Isparta Uygulamalı Bilimler Üniversitesi, Teknoloji Fakültesi, İnşaat Mühendisliği Bölümü, Isparta, Türkiye
}

\begin{abstract}
Anahtar Kelimeler Öz

Sicaklik,

Trend Analizi,

Mann-Kendall Testi,

Sen'in Trend Eğim Testi.

Meteorolojik bir veri olan sıcaklık, iklim değiş̧ikliği ve küresel ısınmanın en önemli göstergelerinden biridir. Bir parametrenin zaman içerisindeki değişimini bilmek, o parametrenin gelecekte nasıl bir davranış göstereceği konusunda fikir sahibi olunmasını sağlamaktadır. Bu çalışmada birbirine komşu olan Çankırı ve Kastamonu illerinde bulunan meteoroloji istasyonlarının maksimum, minimum ve ortalama sıcaklık verileri için trend analizi yapılmıştır. Çalışmada bu iki ilde bulunan toplam sekiz meteoroloji istasyonunun verileri kullanılmıștır. Meteoroloji Genel Müdürlüğ̈’nden 1980-2017 yılları arasında bulunan 38 yıla ait sıcaklık verileri temin edilmiştir. Trend analizi için parametrik olmayan Mann-Kendall Testi kullanılırken, birim zamandaki değişim miktarının belirlenmesi için Sen'in Trend Eğim Testi kullanılmıştır. Maksimum sıcaklıkların trend analizi sonuçlarında sekiz istasyondaki toplam 136 trend analizinden 61 tanesinde istatistiksel açıdan anlamlı artıș trendi belirlenmiștir. Minimum sıcaklıkların trend analizi sonuçları incelendiğinde 41 anlamlı artış trendi elde edilmiștir. Ortalama sıcaklıkların trend analizi sonuçlarına göre ise 136 analizden 52 tanesinin istatistiksel olarak anlamlı artış trendi sergilediği görülmüştür. Trend analizi sonuçları göstermiş̦tir ki Çankırı ve Kastamonu illerinde sıcaklıklar artış eğilimindedir. Yapılan çalışma sonucunda Çankırı ve Kastamonu illerinde gelecek dönemlerde iklim değişikliği ve küresel ısınmanın etkisiyle sıcaklıklarda artış gözleneceği söylenebilir.
\end{abstract}

\section{TREND ANALYSIS OF TEMPERATURE DATA: CASE STUDY OF ÇANKIRI AND KASTAMONU}

\author{
Keywords \\ Temperature, \\ Trend Analysis, \\ Mann-Kendall Test, \\ Sen's Trend Slope Test.
}

\begin{abstract}
Temperature is one of the most important indicators of climate change and global warming. Knowing the change of this parameter over time provides an idea about how that parameter will behave in the future. In this study, trend analysis was applied to the maximum, minimum and average temperature data of meteorology stations located in neighboring provinces, Çankırı and Kastamonu. Data obtained from a total of eight meteorology stations in these two provinces were used in the study. Temperature data for the 38-year period between1980-2017 were obtained from the General Directorate of Meteorology. While the nonparametric MannKendall Test was used for trend analysis, Sen's Trend Slope Test was used to determine the amount of change per unit time. In the trend analysis of the maximum temperatures, a statistically significant increase trend was observed in 61 out of 136 trend analyzes at eight stations. When the trend analysis results of the minimum temperature values are examined, 41 significant increase trend is obtained. The trend analysis results of the average temperature values reveal that 52 out of 136 analyses showed a statistically significant increase trend. Trend analysis results provided that temperature values tend to increase. As a result, it can be concluded that temperature values will increase in Çankırı and Kastamonu in the coming periods due to the climate change and global warming.
\end{abstract}

\footnotetext{
Alıntı / Cite

İlker, A., Terzi, Ö., (2021). Sıcaklık Verilerinin Trend Analizi: Çankırı ve Kastamonu, Mühendislik Bilimleri ve Tasarım Dergisi, 9(4), 1339-1347.
}

\footnotetext{
* ilgili yazar / Corresponding author: mailto:ahmetilker@karatekin.edu.tr, +90-376-213-1195
} 


\begin{tabular}{l|l|l}
\hline Yazar Kimliği / Author ID (ORCID Number) & \multicolumn{3}{|l}{ Makale Süreci / Article Process } \\
\hline A. İlker, 0000-0002-6276-7309 & Başvuru Tarihi / Submission Date & 20.05 .2021 \\
Ö. Terzi, 0000-0001-6429-5176 & Revizyon Tarihi / Revision Date & 28.07 .2021 \\
& Kabul Tarihi / Accepted Date & 04.10 .2021 \\
& Yayım Tarihi / Published Date & 20.12 .2021 \\
\hline
\end{tabular}

\section{Giriș (Introduction)}

İklim değişikliği, iklimin ortalama halinde ve/veya değişkenliğinde uzun periyot boyunca meydana gelen değişiklikler şeklinde tanımlanır (Türkeş, 2008). Üzerinde yaşadığımız yerkürenin oluşumundan başlayarak jeolojik oluşumlar ve bununla birlikte özellikle son yüzyılda insanların çevreyle olan ilişkileri sebebiyle iklim değişimi az veya çok gerçekleşmiştir. Nüfusta meydana gelen hızlı artışlar, insanların giderek artan şehirleşme oranı ve bununla birlikte sanayileşmede yaşanan artışlar, yeraltı sularının bilinçsiz tüketimi ve tüm bunların ötesinde sera gazı salınımında büyük artışların meydana gelmesiyle artan küresel ısınma ve hidrolojik çevrimin olumsuz etkilenmesi sebebiyle dünyamızda bölgesel ve küresel olarak iklim değişikliği görülmektedir (Özyıldırım, 2019).

Küresel ısınma etkisi ile meydana gelen iklim değişikliğinin etkileri özellikle sıcaklık ve yağışta meydana gelen değişimler şeklinde görülmektedir. Bununla birlikte iklim değişikliği, buharlaşma gibi hidrolojik döngünün unsurlarını, tarım ve orman alanları ile bitkilerin doğal yaşam alanlarını, tarımsal çeșitlilik ve verim gibi birçok parametreyi olumsuz yönde etkilemektedir (Çiflik, 2012). Ayrıca küresel ısınma sebebiyle sıcaklık ve yağıșlarda meydana gelen değişimlerin akımları etkilemesi sebebiyle var olan su yapıları planlanan su potansiyelini karșllamada olumsuz yönde etkilenmektedir (Biberoğlu, 2011).

Herhangi bir rastgele değişkenin değerinde zamanla bir artış ya da azalış meydana gelmesine trend denir (Cebe, 2007). Bir değişkendeki trendi belirlemek, o değișkenin geçmiște nasıl bir davranış gösterdiği hakkında bilgi sahibi olunmasını sağlamanın yanında geleceğe dair tahmin yürütülmesini de kolaylaştırmaktadır. Küresel ısınma ve iklim değişikliğinin en önemli göstergelerinden biri olan sıcaklığın geçmişteki davranışını belirlemek amacıyla yapılan trend analizi sıcaklıkta gelecek dönemlerde nasıl bir değişim meydana gelebileceği konusunda güçlü tahminler yapılmasını sağlamaktadır. Bu şekilde gelecek dönemlerde sıcaklıklarda meydana gelecek değişikliklerin olumsuz etkilerinden korunmak amacıyla alınabilecek önlemler belirlenebilmektedir. Hidrometeorolojik verilerde iklim değişikliği sebebiyle meydana gelebilecek değişimleri geçmișe dayanarak tahmin etmek amacıyla trend analizi işlemi yaygın șekilde kullanılmaktadır.

\section{Kaynak Araștırması (Literature Survey)}

Sıcaklık, yağış, vb. gibi hidro-meteorolojik verilerin trendlerini belirlemek amacıyla ülkemizde ve dünyada birçok çalıșma yapılmaktadır. Bu çalışmalardan bazıları bu kısımda özetlenmiștir. Kızılelma vd. (2015) İç Anadolu Bölgesi'nde lineer regresyon ve parametrik olmayan yöntemlerle sıcaklık ve yağışın trend analizini yapmışlardır. Minimum ve maksimum sıcaklıklarda çalışma bölgesi genelinde, ortalama sıcaklıklarda ise Ürgüp istasyonu haricindeki istasyonlarda artış trendi belirlediklerini ifade etmişlerdir. Bununla birlikte yağışlarda genel olarak azalma eğilimi olduğunu belirtmişlerdir. Ülke ve Özkaca (2018) Sen'in Trend Eğim Testi ve Mann-Kendall Testi yöntemlerini kullanarak Ordu, Samsun ve Sinop illerinde sıcaklıkların trend analizini yapmıșlardır. Sıcaklıklarda genellikle artış trendi elde ettiklerini söylemişlerdir. Ay ve Özyıldırım (2017) Yozgat ilinin yağış ve sıcaklık verilerine Yenilikçi Şen yöntemi ve Mann-Kendall Testi ile trend analizi yapmışlardır. Mann-Kendall Testi ile sıcaklık ve yağışlarda anlamlı trend bulamadıklarını ifade etmişlerdir. Yenilikçi Şen yönteminde 1970-1992 yılları arasında yağışlarda artan trend olduğunu, 1993-2016 yılları arasında ise sıcaklıkta artan trend olduğunu tespit etmişlerdir. Tokgöz ve Partal (2020) Karadeniz Bölgesinde bulunan 16 meteoroloji istasyonunun sıcaklık ve yağış verilerine Mann-Kendall Testi ve Yenilikçi Șen yöntemi ile trend analizi uygulamışlardır. Sıcaklık verilerinde Yenilikçi Şen yöntemine göre tüm istasyonlarda, Mann-Kendall Testine göre ise yedi istasyonda artan trend tespit ettiklerini, yağıș verileri için de sıcaklık verilerine yaklaşık sonuçlar elde ettiklerini ifade etmișlerdir. Tabari ve Talaee (2011) İran'da yarı kurak ve kurak bölgelerde bulunan 19 istasyonun maksimum ve minimum sıcaklık verilerine aylık, mevsimlik ve yıllık olarak trend analizi uygulamıșlardır. Minimum ve maksimum sıcaklıklarda son yıllarda artış trendi olduğunu, minimum sıcaklıklardaki artışın maksimum sıcaklıklara göre daha fazla olduğunu söylemişlerdir. Oğuz ve Oğuz (2020) Şanlıurfa ve çevresinde bulunan dokuz meteoroloji istasyonunun sıcaklık ve yağış verilerine trend analizi uygulamışlardır. Elde ettikleri sonuçlara göre sıcaklık verilerinde artış trendi, yağış verilerinde ise azalış trendi olduğunu ifade etmişlerdir. Demir vd. (2017) Bingöl ilinin 1975-2016 yılları arasındaki 42 yıllık döneme ait maksimum, minimum ve ortalama sıcaklık ile yağış verilerine Mann-Kendall ve Spearman testleriyle trend analizi yapmışlardır. Sıcaklık ve yağış verilerinde istatistiksel olarak anlamlı trend olmadığını, bununla birlikte yağışta istatistiksel açıdan anlamsız azalan trend, sıcaklıkta ise istatistiksel açıdan anlamsız artan trend olduğunu söylemişlerdir. Özfidaner vd. (2018) Antalya ili meteoroloji istasyonunun 42 yıllık (1976-2017) 
sıcaklık verilerine trend analizi uygulamışlardır. Yaptıkları çalışmada sıcaklıkta istatistiksel olarak anlamlı artış trendi elde ettiklerini, artış miktarının ise $0,038^{\circ} \mathrm{C}$ /yıl olduğunu ifade etmişlerdir. Ercan ve Yüce (2018) Kilis ilinin meteoroloji istasyonuna ait sıcaklık ve yağış verileriyle Mann-Kendall Testini kullanarak trend analizi yapmışlardır. Elde ettikleri sonuçlara göre maksimum sıcaklıklarda Haziran ayında, ortalama sıcaklıklarda Mayıs ayı dışındaki aylarda artan trend olduğunu söylemişlerdir. Yağıșlarda ise istatistiksel olarak anlamlı bir trend olmadığını belirtmișlerdir. Öztürk ve Cebeci (2021) Büyük Menderes Havzası'nda bulunan Ușak, Aydın ve Denizli illerinin sıcaklık, akım ve yağış verilerine Mann-Kendall Testiyle trend analizi uygulamışlardır. Aydın ilinde sıcaklıklarda trend olmadığını, Uşak ilinde yaz aylarında artan trend olduğunu, Denizli ilinde ise yedi ayda artan trend olduğunu söylemişlerdir. Yağışlarda Aydın ve Denizli'de trend yok iken Uşak'ta sadece Nisan ayında artış trendi olduğunu belirtmişlerdir. Akım verilerinde ise inceledikleri iki istasyonda da azalma trendi olduğunu ifade etmişlerdir. Keskin vd. (2018) Ağrı, Ardahan, Bingöl, Bitlis, Elazığ, Erzincan, Erzurum, Hakkari, Iğdır, Kars, Malatya, Muş, Tunceli ve Van illerinde Mann-Kendall Testi ile yağış ve sıcaklığın trend analizini yapmışlardır. Sıcaklıkların trend analizinde 14 ilden 12 tanesinde istatistiksel olarak anlamlı artış trendi olduğunu tespit etmişlerdir. Sadece Bitlis ve Erzurum illerinde istatistiksel olarak anlamlı trendin olmadığını ifade etmişlerdir. Yağış verilerinin trend analizi sonuçlarına göre 14 ilden 12 tanesinde istatistiksel olarak anlamlı bir trend olmadığını, sadece Kars ve Ardahan illerinde istatistiksel açıdan anlamlı artış trendi olduğunu belirtmişlerdir. Coşkun (2020) Van Gölü kapalı havzasında bulunan Ahlat, Erciş, Gevaş, Muradiye, Özalp, Tatvan ve Van-Bölge istasyonlarının yağış verilerine Mann-Kendall, Spearman'ın Rho ve Şen Testlerini kullanarak trend analizi yapmıștır. Ahlat ve Gevaş istasyonlarında yıllık yağışlarda istatistiksel olarak anlamlı azalma trendi olduğunu, Erciş ve Ahlat istasyonlarında mevsimsel olarak istatistiksel açıdan anlamlı azalma trendi olduğunu ifade etmiștir. Bununla birlikte Muradiye istasyonunda kış mevsimi haricindeki dönemlerde ve Tatvan istasyonunda istatistiksel olarak anlamlı bir trend tespit edilmediğini belirtmiştir. Bolat vd. (2017) Bolu, Karabük ve Kastamonu il merkezlerinde bulunan meteoroloji istasyonlarının maksimum, minimum ve ortalama sıcaklık ile maksimum ve toplam yağış verilerindeki 1980-1999 ile 2000-2015 yılları arasındaki değişimleri incelemişlerdir. Elde ettikleri sonuçlara göre aylık olarak minimum ve maksimum sıcaklıklarda önemli artışlar olduğunu belirtmişlerdir. Bunun yanında ortalama sıcaklık verilerinin üç ilde de özellikle yaz aylarında artış trendinde olduğunu ifade etmişlerdir. Yağış verilerinin sonuçlarında Karabük ilinde aylık ve yıllık ortalama yağış verilerinde azalma trendi, Kastamonu ve Bolu illerinde ise Temmuz ve Ağustos aylarında azalma trendi tespit ettiklerini ifade etmişlerdir.

Bu çalışmada, birbirine komşu olan Çankırı ve Kastamonu illerinde bulunan toplam sekiz meteoroloji istasyonunun (Çankırı, Çerkeş, Ilgaz, Kastamonu, Bozkurt, Devrekani, İnebolu, Tosya) maksimum, minimum ve ortalama sıcaklık verilerine trend analizi uygulanmıştır. Her bir istasyon için bu verilere aylık, mevsimlik ve yıllık olmak üzere Mann-Kendall ve Sen'in Trend Eğim testleri kullanılarak trend analizi yapılmıștır.

\section{Materyal ve Yöntem (Material and Method)}

\section{1. Çalışma Bölgesi (Study Area)}

İç Anadolu Bölgesi'nin Doğu-Batı doğrultusunda yer alan Çankırı 7490 km²'lik yüzölçümüyle ülkemiz topraklarının \% 1'ini oluşturmaktadır. Kuzeyinde Kastamonu, güneyinde Ankara ve Kırıkkale illeri ile komşuyken, doğusunda ve batısında sırasıyla Çorum ve Bolu illeri ile komşudur. İlin Güneydoğu kesiminde bulunan topraklarının bir kısmı Kızılırmak Havzası sınırları içinde bulunurken buralarda sulanabilir geniş ve düz araziler yer almaktadır. Diğer kesimlerde mera, meyilli araziler, orman ve küçük vadilerden oluşan araziler bulunmaktadır. Genel jeolojik yapısı dağlık olan ilde çeşitli yüksekliklerde 18-20 dağ bulunmaktadır. Bunlardan Bozkır dağı 1050 metre ile en alçak, 2587 metre ile Ilgaz dağı en yüksek dağdır. Merkezin rakımı ise 750 metredir. Bu engebeli yapı tarımsal dezavantaj oluşturmaktadır. İlin kuzey doğusundan gelen Acıçay, bir kavis çizerek şehri ikiye ayıran ve kuzeybatıdan gelen Tatlıçay ile birleşip Acısu adını almıştır ve Acısu, Kızılırmak nehrine karışmaktadır. Türkiye'nin en uzun akarsularından biri olan Kızılırmak Nehri'nin bir kısmı ilin topraklarından geçmektedir. Bunun dışında Devrez, Terme, Uluçay ve Melan ilin diğer akarsularıdır. Son beş yıllık meteorolojik veriler il genelinde yağış ortalamasının $522,2 \mathrm{~mm}$, sıcaklık ortalamasının $21^{\circ} \mathrm{C}$ olduğunu göstermiștir (URL 1). İlin ülkemizde yer alan konumu Șekil 1'de verilmiștir.

Ülkemizin Karadeniz Bölgesi'nin Batı Karadeniz Bölümü'nde yer alan Kastamonu ili 13108 km²’lik yüz ölçümüyle ülke topraklarının \%1,7'sini oluşturmaktadır (Şekil 1). Kuzeyinde Karadeniz, doğusunda Sinop, güneydoğusunda Çorum, güneyinde Çankırı, güneybatısında Karabük ve batısında Bartın illeri ile komşudur. Kastamonu genellikle engebeli arazilerden oluşmaktadır, ilin sınırları içerisinde çeşitli yüksekliklerde dağlar bulunmakla birlikte bunların en yükseği $2565 \mathrm{~m}$ ile Çatalılgaz tepesidir. İl genelinde engebeli coğrafya hakim olduğundan geniş ovalar bulunmamakla birlikte vadiler etrafındaki ovacıklar dikkat çekmektedir. Bunlardan en önemlisi Gökırmak Vadisi'dir. Bunun yanında Devrez Vadi'sinin Kastamonu sınırlarında Tosya Ovası mevcuttur. Ayrıca, Araç ve Daday çaylarının oluşturduğu çok küçük ovalar da bulunmaktadır. İlin kuzeyinde Karadeniz iklimi etkili olurken, güneye bakıldığında bulunduğu kesim itibariyle İç Anad olu ikliminin etkileri görülmektedir. İl merkezinde yıllık ortalama 
sıcaklık 9,8 ${ }^{\circ} \mathrm{C}$ 'dir. Bununla birlikte yıllık yağıș ortalaması ise 449,7mm'dir. Yıllık yağıșın aylara göre dağılımı düzenli bir görünüm göstermektedir (URL 2).

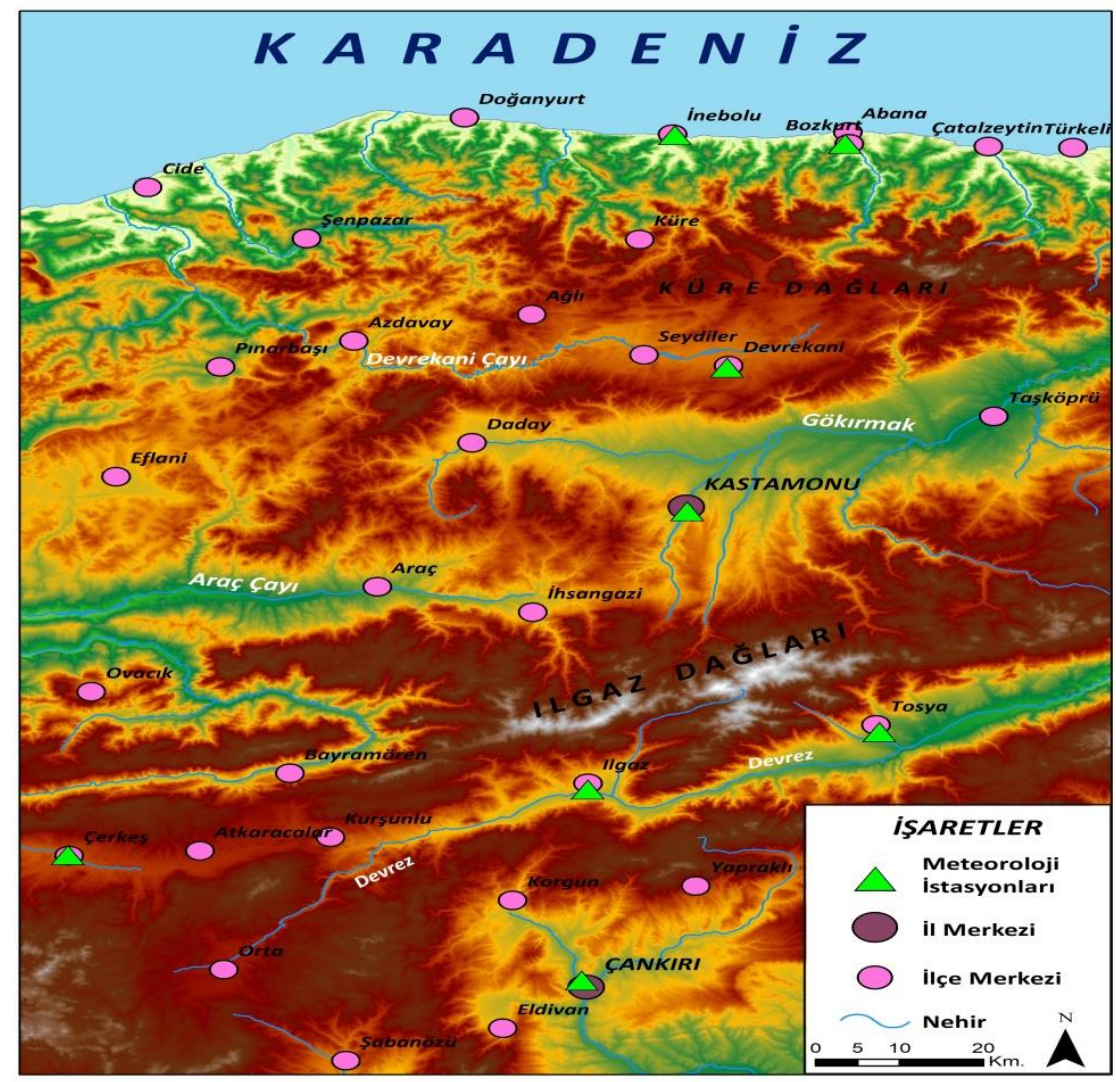

Şekil 1. Çankırı ve Kastamonu İllerinin Ülkemizdeki Konumu (The Position of Çankırı and Kastamonu Provinces in Our Country)

\subsection{Trend Analizi (Trend Analysis)}

\subsubsection{Mann-Kendall Testi (Mann-Kendall Test)}

Parametrik olmayan bir test olan Mann-Kendall sıra tabanlı özelliktedir. Bu test sıcaklık, yağış gibi hidrometeorolojik verilerin trendlerini belirlemede sıkça kullanılan bir yöntemdir. Parametrik olmayan testler, hidrometeorolojik veriler gibi normal olarak dağılım göstermeyen veriler için ve veri grubunda eksiklikle karşılaşılan veriler için trend analizinde parametrik testlere göre daha uygun sonuçlar verir. Bu nedenle parametrik olmayan testler hidro-meteorolojik verilerin trend analizinde tercih edilmektedir.

Mann-Kendall Testi, $S$ tabanlı test istatistiği eşitlik 1 ile hesaplanır.

$$
S=\sum_{i=1}^{n-1} \sum_{j=i+1}^{n} \operatorname{sgn}\left(x_{j}-x_{i}\right)
$$

burada $x_{j}, x_{i}$ sıralı veri değerlerini, $n$ veri sayısını ifade eder. Bu eşitlikteki $\left(x_{j}-x_{i}\right)$ değerinin işareti eşitlik 2 ile hesaplanır (Yue vd., 2002).

$$
\operatorname{sgn}(\theta)=\left\{\begin{array}{cc}
+1 & \text { Ĕger }(\theta)>0 \\
0 & \text { Ĕer }(\theta)=0 \\
-1 & \text { Ĕg er }(\theta)<0
\end{array}\right.
$$

Mann (1945) ve Kendall (1948) $n \geq 8$ olduğunda $S$ istatistiğinin eşitlik 3 ve 4'te verilen ortalama ve varyans istatistiklerine uygun olarak normal dağıldığını ifade etmişlerdir. 


$$
E(S)=0
$$

Burada $E$ ortalamayı ifade etmektedir.

$$
V(S)=\frac{n(n-1)(2 n+5)-\sum_{i=1}^{n} t_{i} i(i-1)(2 i+5)}{18}
$$

Burada $n$ veriler içindeki nispi grupların sayılarını, $t_{i}, i$ uzunluğundaki bir seride bağlı gözlemleri ifade etmektedir. Standartlaştırılmış test istatistiği $Z$ eşitlik 5 ile hesaplanmaktadır (Kendall, 1948).

$$
Z=\left\{\begin{array}{lll}
\frac{S-1}{\sqrt{\operatorname{Var}(S)}} & \text { Ĕer } & S>0 \\
0 & \text { Ĕg er } & S=0 \\
\frac{S+1}{\sqrt{\operatorname{Var}(S)}} & \text { Ĕger } & S<0
\end{array}\right\}
$$

Seçilmiş olan $\alpha$ anlamlılık seviyesinde $|z| \leq z_{\alpha}$ şartı sağlanıyorsa hipotez H0 kabul, sağlanmıyorsa reddedilir. Yukarıdaki eşitlikte verilen $S$ değeri negatif ise azalan, pozitif ise artan trend olduğu kabulü yapılır.

\subsubsection{Sen'in Trend Eğim Testi (Sen's Trend Slope Test)}

Sen (1968) tarafından geliştirilen bu parametrik olmayan yöntem ile doğrusal bir trend mevcut olduğu taktirde birim zamandaki değişiklik (gerçek eğim) tahmin edilebilir. Bu test veri grubunda eksiklik bulunması durumunda kullanılabilir. Bununla birlikte testin aykırı değerlerden ve büyük veri hatalarından etkilenme ihtimali çok düşüktür. Testte hesaplamalar aşağıdaki şekilde yapılır. Öncelikle $N$ veri çiftinin eğim tahminleri eşitlik 6 ile hesaplanir.

$$
Q=\frac{\left(x_{j}-x_{k}\right)}{j-k}
$$

Burada $x_{j}$ ve $x_{k}$ sirasıyla j ve $k(j>k$ şartıyla) zamanlarındaki verilerdir. $N$ değerlerinin medyanı olan $Q$, Sen'in eğim tahmin edicisidir. Bütün zaman periyotlarında tek bir referans olduğunda eşitlik 7 kullanılır.

$$
N=\frac{n(n-1)}{2}
$$

Burada n zaman periyotlarının sayısını ifade eder. $N$ eğim tahminlerinin medyanı alışılagelmiş şekilde elde edilir. $N$ adet $Q$ değeri, $Q_{1} \leq Q_{2} \leq \ldots \leq Q_{n-1} \leq Q_{n}$ şeklinde sıralanır ve $N$ tek ise eşitlik $8, N$ çift ise eşitlik 9 kullanılır.

$$
\begin{gathered}
\text { Sen'in Tahmincisi }^{\prime}=Q_{[(N+1) / 2]} \\
\text { Sen'in Tahmincisi }=\frac{1}{2}\left[Q_{(N / 2)}+Q_{[(N+2) / 2]}\right]
\end{gathered}
$$

$\mathrm{Bu}$ şekilde test edilen verilerin birim zamandaki değişimi bulunur. Sen (1968) tarafından verilen parametrik olmayan teknik aracılığıyla iki taraflı test ile \%100 (1- $\alpha)$ güven aralığında test edilerek gerçek eğim saptanır (Yu vd., 1993).

\section{Araştırma Bulguları (Research Findings)}

Çalışma bölgesi olarak seçilen Çankırı ve Kastamonu illerinde bulunan toplam sekiz meteoroloji istasyonunun maksimum, minimum ve ortalama sıcaklık verilerinde trend analizi gerçekleștirilmiştir. Çalışmada kullanılan veriler Meteoroloji Genel Müdürlüğü'nden (MGM) temin edilmiştir. Trend varlığı araştırılan veriler 1980-2017 yılları arasındaki 38 yıllık dönemi kapsamaktadır. Hidro-meteorolojik verilerde trend belirlemek için sıklıkla kullanılan parametrik olmayan Mann-Kendall Testi trend varlığını araştırmak için kullanılmıştır. Kullanılan verilerde trend varlığı 0,05 anlamlılık seviyesinde, diğer bir ifadeyle \%95 güven aralığında değerlendirilmiștir. Z $\geq+1,96$ ise artan trend, $Z \leq-1,96$ ise azalan trend olarak kabul edilmiștir. $Z$ değeri $+1,96$ ile $-1,96$ arasında ise istatistiksel açıdan anlamlı bir trend olmadığı kabul edilmiştir. Ayrıca Sen'in Trend Eğim Testi verilerdeki birim 
zamanki değişim miktarını saptamak için kullanılmıştır. İç bağımlılık bulunan veri serilerine iç bağımlılık ortadan kaldırılmadan trend analizi uygulanması durumunda trend analizi hatalı sonuçlar verecektir. Örneğin trend olmayan yerde var, var olan yerde ise yok sonucu ortaya çıkacaktır (Bayazit ve Önöz, 2007). Bunun için veri serilerinde otokorelasyon kontrolü yapılarak, otokorelasyon tespit edilenlere ön beyazlatma işlemi uygulanarak iç bağımlılık ortadan kaldırılmıștır. Bu șekilde veriler trend analizi uygulanmaya hazır hale getirilmiștir. Her bir istasyon için 12 ay, dört mevsim ve yıllık olmak üzere toplam 17 trend analizi yapılmıștır. İlkbahar mevsimi; Mart, Nisan, Mayıs, yaz mevsimi; Haziran, Temmuz, Ağustos, sonbahar mevsimi; Eylül, Ekim, Kasım ve kış mevsimi; Aralık, Ocak, Şubat ayları olarak kullanılmıştır.

\subsection{Maksimum Sicaklıkların Trend Analizi (Trend Analysis of Maximum Temperatures)}

Maksimum sıcaklıkların trend analizi sonuçlarına göre mevsimlik olarak yapılan analizde sonbahar mevsiminde sekiz meteoroloji istasyonunun tamamında istatistiksel olarak anlamlı artış trendi olduğu gözlenmiştir. Buna karşılık aylık analiz sonuçlarına göre Ocak, Nisan, Ekim ve Aralık ayları için sekiz meteoroloji istasyonunun hiçbirinde istatistiksel açıdan anlamlı bir trend belirlenmemiştir. Ayrıca istatistiksel analizi yaplan sekiz meteoroloji istasyonundan Bozkurt ve İnebolu istasyonları dışındaki istasyonlarda yıllık olarak anlamlı artış trendi saptanmıştır. Maksimum sıcaklıkların trend analizi sonuçlarının verildiği Tablo 1 incelendiğinde sekiz istasyon için toplam 136 trend analizi yapıldığı görülmektedir. Bu analizlerinden 61 tanesi istatistiksel olarak anlamlıdır ve artış trendi şeklindedir. Geriye kalan 75 analiz istatistiksel açıdan anlamsız olmakla birlikte büyük çoğunluğu artış trendi şeklindedir. Bunlardan sadece dört tanesinin azalış trendi olduğu görülmektedir. Anlamsız azalış trendlerinin Çankırı, Ilgaz, Kastamonu ve Devrekani istasyonlarında ve Ocak ayında olduğu tespit edilmiştir. Sen'in Trend Eğim Testi sonuçları incelendiğinde, istatistiksel olarak anlamlı trendlerin görüldüğü yerlerde en az artış miktarının 0,026 ำ/yll ile İnebolu istasyonunda, en çok artış miktarının 0,117 ํㅡ/yıl ile Çerkeş istasyonunda olduğu saptanmıştır.

Tablo 1. Maksimum Sıcaklık Verilerinin Trend Analizi Sonuçları (Trend Analysis Results of Maximum Temperature Data)

\begin{tabular}{|c|c|c|c|c|c|c|c|c|c|c|c|c|c|c|c|c|}
\hline & \multicolumn{2}{|c|}{ Çankırı } & \multicolumn{2}{|c|}{ Çerkeş } & \multicolumn{2}{|c|}{ Ilgaz } & \multicolumn{2}{|c|}{ Kastamonu } & \multicolumn{2}{|c|}{ Bozkurt } & \multicolumn{2}{|c|}{ Devrakani } & \multicolumn{2}{|c|}{ İnebolu } & \multicolumn{2}{|c|}{ Tosya } \\
\hline & Trend & $\begin{array}{l}\text { Sen'in } \\
\text { Trend } \\
\text { Eğim } \\
\text { Testi }\end{array}$ & Trend & $\begin{array}{c}\text { Sen'in } \\
\text { Trend } \\
\text { Eğim } \\
\text { Testi }\end{array}$ & Trend & $\begin{array}{l}\text { Sen'in } \\
\text { Trend } \\
\text { Eğim } \\
\text { Testi } \\
\end{array}$ & Trend & $\begin{array}{l}\text { Sen'in } \\
\text { Trend } \\
\text { Eğim } \\
\text { Testi } \\
\end{array}$ & Trend & $\begin{array}{c}\text { Sen'in } \\
\text { Trend } \\
\text { Eğim } \\
\text { Testi }\end{array}$ & Trend & $\begin{array}{c}\text { Sen'in } \\
\text { Trend } \\
\text { Eğim } \\
\text { Testi }\end{array}$ & Trend & $\begin{array}{c}\text { Sen'in } \\
\text { Trend } \\
\text { Eğim } \\
\text { Testi }\end{array}$ & Trend & $\begin{array}{c}\text { Sen'in } \\
\text { Trend } \\
\text { Eğim } \\
\text { Testi }\end{array}$ \\
\hline $\mathbf{0}$ & --- & $-0,028$ & -- & 0,006 & --- & $-0,020$ & --- & $-0,012$ & --- & 0,029 & --- & $-0,031$ & --- & 0,016 & --- & 0,010 \\
\hline $\mathbf{S}$ & --- & 0,093 & $\uparrow$ & 0,117 & $\uparrow$ & 0,115 & $\uparrow$ & 0,115 & $\uparrow$ & 0,090 & $\uparrow$ & 0,102 & $\uparrow$ & 0,068 & $\uparrow$ & 0,112 \\
\hline M & --- & 0,058 & --- & 0,075 & $\uparrow$ & 0,088 & $\uparrow$ & 0,076 & $\uparrow$ & 0,082 & --- & 0,043 & --- & 0,061 & $\uparrow$ & 0,080 \\
\hline $\mathbf{N}$ & --- & 0,045 & -- & 0,049 & --- & 0,079 & --- & 0,066 & --- & 0,045 & --- & 0,014 & -- & 0,046 & --- & 0,063 \\
\hline M & --- & 0,045 & $\uparrow$ & 0,071 & --- & 0,053 & $\uparrow$ & 0,056 & --- & 0,022 & --- & 0,032 & --- & 0,024 & $\uparrow$ & 0,062 \\
\hline $\mathbf{H}$ & $\uparrow$ & 0,065 & -- & 0,033 & --- & 0,044 & --- & 0,028 & --- & 0,015 & --- & 0,022 & $\uparrow$ & 0,032 & $\uparrow$ & 0,072 \\
\hline $\mathbf{T}$ & $\uparrow$ & 0,079 & $\uparrow$ & 0,073 & $\uparrow$ & 0,074 & --- & 0,067 & -- & 0,025 & $\uparrow$ & 0,089 & --- & 0,025 & $\uparrow$ & 0,068 \\
\hline A & $\uparrow$ & 0,090 & --- & 0,073 & $\uparrow$ & 0,115 & $\uparrow$ & 0,105 & --- & 0,036 & $\uparrow$ & 0,097 & $\uparrow$ & 0,044 & --- & 0,059 \\
\hline $\mathbf{E}$ & --- & 0,019 & --- & 0,045 & --- & 0,052 & --- & 0,047 & $\uparrow$ & 0,072 & --- & 0,037 & --- & 0,043 & $\uparrow$ & 0,057 \\
\hline $\mathbf{E}$ & --- & 0,001 & --- & 0,036 & --- & 0,030 & --- & 0,023 & --- & 0,027 & --- & 0,008 & --- & 0,032 & --- & 0,038 \\
\hline $\mathbf{K}$ & $\uparrow$ & 0,083 & $\uparrow$ & 0,116 & $\uparrow$ & 0,090 & $\uparrow$ & 0,098 & $\uparrow$ & 0,058 & -- & 0,084 & --- & 0,047 & $\uparrow$ & 0,092 \\
\hline A & --- & 0,011 & --- & 0,026 & --- & 0,031 & --- & 0,007 & --- & 0,035 & --- & 0,031 & --- & 0,031 & --- & 0,014 \\
\hline İlkbahar & $\uparrow$ & 0,056 & $\uparrow$ & 0,070 & $\uparrow$ & 0,076 & $\uparrow$ & 0,068 & $\uparrow$ & 0,066 & -- & 0,038 & $\uparrow$ & 0,060 & $\uparrow$ & 0,064 \\
\hline Yaz & --- & 0,043 & $\uparrow$ & 0,046 & $\uparrow$ & 0,046 & --- & 0,036 & --- & 0,029 & --- & 0,036 & $\uparrow$ & 0,026 & --- & 0,042 \\
\hline Sonbahar & $\uparrow$ & 0,042 & $\uparrow$ & 0,072 & $\uparrow$ & 0,065 & $\uparrow$ & 0,065 & $\uparrow$ & 0,054 & $\uparrow$ & 0,042 & $\uparrow$ & 0,054 & $\uparrow$ & 0,068 \\
\hline Kış & --- & 0,032 & $\uparrow$ & 0,060 & --- & 0,047 & --- & 0,035 & $\uparrow$ & 0,047 & --- & 0,042 & --- & 0,040 & --- & 0,042 \\
\hline Yillık & $\uparrow$ & 0,049 & $\uparrow$ & 0,042 & $\uparrow$ & 0,036 & $\uparrow$ & 0,029 & --- & 0,021 & $\uparrow$ & 0,034 & --- & 0,024 & $\uparrow$ & 0,030 \\
\hline
\end{tabular}

---: Trend yok, $\downarrow$ : Azalan trend, $\uparrow:$ Artan trend

\subsection{Minimum Sıcaklıkların Trend Analizi (Trend Analysis of Minimum Temperatures)}

Minimum sıcaklık verilerine uygulanan trend analizi işleminin sonuçları Tablo 2'de verilmiştir. Tablo 2 incelendiğinde Ilgaz meteoroloji istasyonunda 12 ay, dört mevsim ve ylllık olmak üzere hiçbir noktada istatistiksel açıdan anlamlı bir trend görülmemiştir. Ayrıca Ocak, Şubat, Nisan, Mayıs, Kasım, Aralık aylarında ve kış mevsiminde analizi yapılan sekiz istasyonun hiçbirinde anlamlı bir trend belirlenmemiştir. Sonbahar mevsiminde Ilgaz ve Tosya istasyonları dışındaki istasyonlarda, yaz mevsiminde ise Çerkeş ve Ilgaz istasyonları haricindeki 
istasyonlarda istatistiksel olarak anlamlı artış trendi tespit edilmiştir. Ayrıca Çerkeş, Ilgaz ve Tosya istasyonları dışındaki istasyonlarda Haziran ve Eylül aylarında, Çankırı, Çerkeş ve Ilgaz istasyonları haricindeki istasyonlarda ise Ağustos ayında anlamlı artış trendi olduğu saptanmıştır. Analizi gerçekleştirilen sekiz istasyonun hiçbirinde istatistiksel açıdan anlamlı azalıș trendi bulunmadığı görülmüştür. Sekiz istasyon için yapılan trend analizlerinden sadece 41 tanesinin istatistiksel olarak anlamlı olduğu ve tamamının artış trendi şeklinde olduğu Tablo 2'de görülmektedir. Sen'in Trend Eğim Testi sonuçlarına göre 0,070 ํㅡ/yıl ile en büyük artış miktarı Bozkurt istasyonun Ağustos ayı trend analizinde, en küçük artış miktarı ise 0,020 Devrekani istasyonunun yıllık trend analizinde olduğu saptanmıştır. Sen'in Trend Eğim Testi sonuçları sadece anlamlı trend görülen noktalar için değerlendirilmiştir.

Tablo 2. Minimum sıcaklık verilerinin trend analizi sonuçları (Trend Analysis Results of Minimum Temperature Data)

\begin{tabular}{|c|c|c|c|c|c|c|c|c|c|c|c|c|c|c|c|c|}
\hline & \multicolumn{2}{|c|}{ Çankırı } & \multicolumn{2}{|c|}{ Çerkeş } & \multicolumn{2}{|c|}{ Ilgaz } & \multicolumn{2}{|c|}{ Kastamonu } & \multicolumn{2}{|c|}{ Bozkurt } & \multicolumn{2}{|c|}{ Devrakani } & \multicolumn{2}{|c|}{ İnebolu } & \multicolumn{2}{|c|}{ Tosya } \\
\hline & Trend & $\begin{array}{c}\text { Sen'in } \\
\text { Trend } \\
\text { Eğim } \\
\text { Testi }\end{array}$ & Trend & $\begin{array}{l}\text { Sen'in } \\
\text { Trend } \\
\text { Eğim } \\
\text { Testi }\end{array}$ & Trend & $\begin{array}{l}\text { Sen'in } \\
\text { Trend } \\
\text { Eğim } \\
\text { Testi }\end{array}$ & Trend & $\begin{array}{l}\text { Sen'in } \\
\text { Trend } \\
\text { Eğim } \\
\text { Testi }\end{array}$ & Trend & $\begin{array}{l}\text { Sen'in } \\
\text { Trend } \\
\text { Eğim } \\
\text { Testi }\end{array}$ & Trend & $\begin{array}{l}\text { Sen'in } \\
\text { Trend } \\
\text { Eğim } \\
\text { Testi }\end{array}$ & Trend & $\begin{array}{l}\text { Sen'in } \\
\text { Trend } \\
\text { Eğim } \\
\text { Testi }\end{array}$ & Trend & $\begin{array}{c}\text { Sen'in } \\
\text { Trend } \\
\text { Eğim } \\
\text { Testi }\end{array}$ \\
\hline $\mathbf{0}$ & --- & 0,011 & --- & 0,017 & --- & $-0,030$ & --- & 0,010 & --- & 0,015 & --- & $-0,035$ & --- & 0,015 & --- & 0,005 \\
\hline Ş & --- & 0,039 & --- & 0,089 & --- & 0,032 & --- & 0,052 & --- & 0,057 & --- & 0,082 & --- & 0,053 & --- & 0,057 \\
\hline M & $\uparrow$ & 0,049 & $\uparrow$ & 0,068 & --- & 0,027 & --- & 0,048 & $\uparrow$ & 0,046 & --- & 0,061 & $\uparrow$ & 0,042 & --- & 0,051 \\
\hline $\mathbf{N}$ & --- & $-0,009$ & --- & 0,005 & --- & $-0,040$ & --- & $-0,02$ & --- & 0,025 & --- & $-0,013$ & --- & 0,024 & --- & 0,002 \\
\hline $\mathbf{M}$ & --- & 0,030 & --- & 0,021 & --- & $-0,011$ & --- & 0,019 & --- & 0,033 & --- & 0,020 & --- & 0,015 & --- & 0,016 \\
\hline $\mathbf{H}$ & $\uparrow$ & 0,030 & --- & 0,036 & --- & 0,009 & $\uparrow$ & 0,031 & $\uparrow$ & 0,027 & $\uparrow$ & 0,035 & $\uparrow$ & 0,039 & --- & 0,024 \\
\hline $\mathbf{T}$ & --- & 0,031 & --- & 0,019 & --- & 0,010 & --- & 0,027 & --- & 0,021 & $\uparrow$ & 0,040 & --- & 0,015 & --- & 0,039 \\
\hline A & --- & 0,046 & --- & 0,036 & --- & 0,034 & $\uparrow$ & 0,061 & $\uparrow$ & 0,070 & $\uparrow$ & 0,067 & $\uparrow$ & 0,039 & $\uparrow$ & 0,056 \\
\hline $\mathbf{E}$ & $\uparrow$ & 0,047 & --- & 0,046 & --- & 0,002 & $\uparrow$ & 0,040 & $\uparrow$ & 0,044 & $\uparrow$ & 0,057 & $\uparrow$ & 0,052 & --- & 0,026 \\
\hline $\mathbf{E}$ & $\uparrow$ & 0,054 & $\uparrow$ & 0,050 & --- & 0,006 & --- & 0,041 & --- & 0,010 & --- & 0,041 & --- & 0,022 & --- & 0,010 \\
\hline $\mathbf{K}$ & --- & $-0,007$ & --- & 0,022 & --- & $-0,022$ & --- & 0,009 & --- & 0,037 & --- & 0,035 & --- & 0,034 & --- & 0,039 \\
\hline A & --- & $-0,019$ & --- & $-0,005$ & --- & $-0,037$ & --- & $-0,016$ & --- & $-0,004$ & -- & $-0,035$ & --- & $-0,011$ & --- & $-0,023$ \\
\hline İlkbahar & --- & 0,018 & --- & 0,031 & --- & $-0,015$ & --- & 0,016 & $\uparrow$ & 0,032 & --- & 0,018 & $\uparrow$ & 0,032 & --- & 0,018 \\
\hline Yaz & $\uparrow$ & 0,034 & --- & 0,023 & --- & 0,017 & $\uparrow$ & 0,037 & $\uparrow$ & 0,021 & $\uparrow$ & 0,045 & $\uparrow$ & 0,025 & $\uparrow$ & 0,027 \\
\hline Sonbahar & $\uparrow$ & 0,039 & $\uparrow$ & 0,063 & --- & $-0,019$ & $\uparrow$ & 0,030 & $\uparrow$ & 0,034 & $\uparrow$ & 0,036 & $\uparrow$ & 0,038 & --- & 0,022 \\
\hline Kış & --- & 0,017 & --- & 0,042 & --- & $-0,005$ & --- & 0,012 & --- & 0,019 & --- & 0,012 & --- & 0,020 & --- & 0,015 \\
\hline Yıllık & $\uparrow$ & 0,022 & --- & 0,020 & --- & $-0,005$ & $\uparrow$ & 0,021 & --- & 0,018 & $\uparrow$ & 0,020 & $\uparrow$ & 0,021 & $\uparrow$ & 0,025 \\
\hline
\end{tabular}

---: Trend yok, $\downarrow$ : Azalan trend, $\uparrow:$ Artan trend

\subsection{Ortalama Sicaklıkların Trend Analizi (Trend Analysis of Mean Temperatures)}

Çankırı ve Kastamonu illerinde bulunan sekiz meteoroloji istasyonun ortalama sıcaklık verilerinin trend analizi sonuçlarının verildiği Tablo 3 incelendiğinde, Ağustos ayında ve yıllıkta tüm istasyonlarda anlamlı artış trendi olduğu görülmüştür. Diğer taraftan, aylık olarak incelendiğinde Ocak, Nisan, Mayıs, Ekim, Aralık aylarında ve mevsimlik olarak incelendiğinde kış mevsiminde istasyonların hiçbirinde istatistiksel olarak anlamlı trende rastlanmamıştır. Sonbahar mevsiminde Ilgaz meteoroloji istasyonu dışındaki istasyonlarda anlamlı artış trendi olduğu görülmüştür. Buna karşılık Kasım ayında sadece Tosya istasyonunda anlamlı artış trendi görülürken diğer istasyonlarda anlamlı bir trende rastlanmamıştır. Ortalama sıcaklık verilerinde her bir istasyon için 12 ay, dört mevsim ve yıllık olmak üzere 17 trend analizi yapılarak toplamda 136 trend analizi yapıldığı göz önüne alındığında bu trend analizlerinden 52 tanesi istatistiksel açıdan anlamlı ve hepsinin artış trendi şeklinde olduğu görülmüştür. Geriye kalan 84 trend analizi anlamsız olmakla birlikte büyük bir kısmı yine artış trendi şeklindedir. Bunlardan sadece dokuz tanesi anlamsız azalış trendine sahiptir. İstatistiksel olarak anlamlı trend belirlenen yerlerden

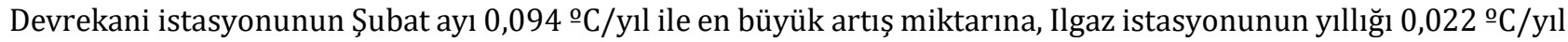
ile en küçük artış miktarına sahip olduğu belirlenmiştir. 
Tablo 3. Ortalama sıcaklık verilerinin trend analizi sonuçları (Trend Analysis Results of Mean Temperature Data)

\begin{tabular}{|c|c|c|c|c|c|c|c|c|c|c|c|c|c|c|c|c|}
\hline & \multicolumn{2}{|c|}{ Çankırı } & \multicolumn{2}{|c|}{ Çerkeş } & \multicolumn{2}{|c|}{ Ilgaz } & \multicolumn{2}{|c|}{ Kastamonu } & \multicolumn{2}{|c|}{ Bozkurt } & \multicolumn{2}{|c|}{ Devrakani } & \multicolumn{2}{|c|}{ İnebolu } & \multicolumn{2}{|c|}{ Tosya } \\
\hline & Trend & $\begin{array}{c}\text { Sen'in } \\
\text { Trend } \\
\text { Eğim } \\
\text { Testi } \\
\end{array}$ & Trend & $\begin{array}{l}\text { Sen'in } \\
\text { Trend } \\
\text { Eğim } \\
\text { Testi } \\
\end{array}$ & Trend & $\begin{array}{l}\text { Sen'in } \\
\text { Trend } \\
\text { Eğim } \\
\text { Testi }\end{array}$ & Trend & $\begin{array}{l}\text { Sen'in } \\
\text { Trend } \\
\text { Eğim } \\
\text { Testi } \\
\end{array}$ & Trend & $\begin{array}{l}\text { Sen'in } \\
\text { Trend } \\
\text { Eğim } \\
\text { Testi } \\
\end{array}$ & Trend & $\begin{array}{l}\text { Sen'in } \\
\text { Trend } \\
\text { Eğim } \\
\text { Testi } \\
\end{array}$ & Trend & $\begin{array}{l}\text { Sen'in } \\
\text { Trend } \\
\text { Eğim } \\
\text { Testi } \\
\end{array}$ & Trend & $\begin{array}{c}\text { Sen'in } \\
\text { Trend } \\
\text { Eğim } \\
\text { Testi } \\
\end{array}$ \\
\hline o & --- & 0,010 & --- & 0,011 & --- & $-0,029$ & --- & 0,000 & --- & 0,019 & -- & $-0,032$ & --- & 0,013 & -- & 0,002 \\
\hline ș & --- & 0,063 & $\uparrow$ & 0,092 & --- & 0,064 & $\uparrow$ & 0,072 & $\uparrow$ & 0,067 & $\uparrow$ & 0,094 & --- & 0,054 & --- & 0,076 \\
\hline M & --- & 0,050 & --- & 0,061 & --- & 0,043 & --- & 0,051 & $\uparrow$ & 0,062 & --- & 0,054 & --- & 0,050 & $\uparrow$ & 0,053 \\
\hline $\mathrm{N}$ & --- & 0,015 & --- & 0,020 & --- & 0,005 & --- & 0,018 & --- & 0,024 & --- & 0,000 & --- & 0,036 & --- & 0,018 \\
\hline M & --- & 0,028 & --- & 0,036 & --- & 0,008 & --- & 0,033 & --- & 0,039 & --- & 0,020 & --- & 0,022 & -- & 0,032 \\
\hline H & $\uparrow$ & 0,051 & --- & 0,027 & $\uparrow$ & 0,044 & $\uparrow$ & 0,041 & --- & 0,013 & $\uparrow$ & 0,044 & $\uparrow$ & 0,030 & $\uparrow$ & 0,032 \\
\hline $\mathbf{T}$ & $\uparrow$ & 0,055 & --- & 0,038 & $\uparrow$ & 0,053 & --- & 0,040 & --- & 0,020 & $\uparrow$ & 0,065 & --- & 0,020 & $\uparrow$ & 0,054 \\
\hline A & $\uparrow$ & 0,081 & $\uparrow$ & 0,075 & $\uparrow$ & 0,060 & $\uparrow$ & 0,078 & $\uparrow$ & 0,044 & $\uparrow$ & 0,076 & $\uparrow$ & 0,036 & $\uparrow$ & 0,066 \\
\hline $\mathbf{E}$ & --- & 0,032 & $\uparrow$ & 0,055 & --- & 0,024 & $\uparrow$ & 0,038 & $\uparrow$ & 0,048 & --- & 0,038 & $\uparrow$ & 0,058 & --- & 0,028 \\
\hline $\mathbf{E}$ & -- & 0,023 & --- & 0,022 & --- & 0,008 & --- & 0,021 & --- & 0,010 & --- & 0,020 & --- & 0,017 & --- & 0,014 \\
\hline $\mathbf{K}$ & --- & 0,025 & --- & 0,043 & --- & 0,013 & --- & 0,039 & --- & 0,046 & --- & 0,050 & --- & 0,042 & $\uparrow$ & 0,056 \\
\hline A & --- & $-0,005$ & --- & $-0,004$ & --- & $-0,032$ & --- & $-0,011$ & --- & 0,015 & -- & $-0,008$ & -- & 0,005 & -- & $-0,009$ \\
\hline Illkbahar & $\uparrow$ & 0,032 & $\uparrow$ & 0,038 & --- & 0,015 & $\uparrow$ & 0,035 & $\uparrow$ & 0,045 & --- & 0,021 & $\uparrow$ & 0,044 & $\uparrow$ & 0,038 \\
\hline Yaz & $\uparrow$ & 0,041 & --- & 0,033 & --- & 0,036 & --- & 0,030 & --- & 0,022 & $\uparrow$ & 0,029 & --- & 0,022 & --- & 0,033 \\
\hline Sonbahar & $\uparrow$ & 0,030 & $\uparrow$ & 0,043 & --- & 0,023 & $\uparrow$ & 0,034 & $\uparrow$ & 0,035 & $\uparrow$ & 0,040 & $\uparrow$ & 0,040 & $\uparrow$ & 0,036 \\
\hline Kış & --- & 0,018 & --- & 0,030 & --- & 0,004 & --- & 0,018 & --- & 0,027 & -- & 0,024 & -- & 0,020 & -- & 0,023 \\
\hline Yillık & $\uparrow$ & 0,033 & $\uparrow$ & 0,031 & $\uparrow$ & 0,022 & $\uparrow$ & 0,036 & $\uparrow$ & 0,024 & $\uparrow$ & 0,039 & $\uparrow$ & 0,024 & $\uparrow$ & 0,038 \\
\hline
\end{tabular}

---: Trend yok, $\downarrow$ : Azalan trend, $\uparrow:$ Artan trend

\section{Sonuç ve Tartışma (Result and Discussion)}

Çankırı ve Kastamonu illerinde bulunan il merkezleri meteoroloji istasyonları da dahil olmak üzere toplam sekiz meteoroloji istasyonunun 1980-2017 yılları arasındaki 38 yıllık döneme ait maksimum, minimum ve ortalama sıcaklık verileri Meteoroloji Genel Müdürlüğü’nden elde edilerek, her bir istasyon için ayrı ayrı 12 ay, dört mevsim ve yıllık olmak üzere Mann-Kendall Testi kullanılarak trend analizi yapılmıştır. Bunun yanında Sen'in Trend Eğim Testi birim zamandaki değişim miktarını araştırmak amacıyla kullanılmıştır.

Çalışmada yapılan maksimum sıcaklıkların trend analizi sonuçlarına göre incelenen istasyonların tamamında sonbahar mevsiminde anlamlı artış trendi görülmesi maksimum sıcaklıklarda gelecek dönemlerde özellikle sonbahar mevsiminde pik değerler görüleceğini düşündürmektedir. Ayrıca yapılan analizlerde incelenen istasyonların büyük çoğunluğunda belirtilen noktalarda anlamlı artış trendi saptanması bugüne kadar ölçülen maksimum sıcaklık değerlerinin gelecek dönemlerde daha da yüksek değerler ölçülebileceğini göstermektedir. Buna örnek olarak Şubat ayı için Çankırı istasyonu haricindeki, ilkbahar mevsimi için Devrekani istasyonu haricindeki ve yıllık olarak ise Bozkurt ve İnebolu istasyonları haricindeki diğer istasyonlarda verilebilir.

Minimum sıcaklıkların trend analizinde birçok noktada anlamlı artış trendi görülmesiyle birlikte özellikle yaz mevsiminde Çerkeş ve Ilgaz istasyonları haricindeki istasyonlarda, sonbahar mevsiminde ise Ilgaz ve Tosya istasyonları haricindeki istasyonlarda anlamlı artış trendi görülmesi incelenen istasyonların genelinde yaz ve sonbahar mevsimlerinde gelecek dönemler için sıcaklıklarda artış görüleceğini düşündürmektedir. Bununla birlikte en düşük sıcaklık değerlerinde bile birçok anlamlı artış trendinin belirlenmiş olması incelenen istasyonlarda gelecek dönemlerde sıcaklıklarda artışların meydana gelebileceğini göstermektedir.

Ortalama sıcaklıkların trend analizi sonuçları değerlendirildiğinde ise, sonbahar mevsiminde Ilgaz istasyonu dışındaki, ilkbahar mevsiminde Ilgaz ve Devrekani istasyonları dışındaki ve Haziran ayında Çerkeş ve Bozkurt istasyonları dışındaki istasyonlarda ve Ağustos ayı ile yıllık olarak incelenen istasyonların tümünde anlamlı artış trendinin görülmesi, belirtilen noktalarda istasyonların genelinde gelecek dönemlerde sıcaklıklarda artışların oluşabileceğini göstermektedir.

Çankırı ve Kastamonu illerinde bulunan sekiz meteoroloji istasyonunun maksimum, minimum ve ortalama sıcaklık verilerinin trend analizi sonuçları genel olarak değerlendirildiğinde, sekiz istasyon için toplam 408 analiz yapılmıştır. Bu analizlerden 154 tanesi istatistiksel olarak anlamlı ve tamamının artış trendinde olduğu saptanmıştır. Geriye kalan 254 analizin istatistiksel olarak anlamsız olduğu, bunların da 221 tanesinin yine artış 
trendine sahip olduğu, sadece 33 tanesinin azalış trendinde olduğu görülmüștür. Buna dayanarak incelenen istasyonlarda sıcaklıklarda artış trendi olduğunu söylemek mümkündür. Ayrıca yapılan analizlerin \%95 güven aralığında değerlendirildiği düşünülür ise \% 90 güven aralığında değerlendirildiğinde istatistiksel olarak anlamlı trendlerin sayısının artacağı açıktır.

Nüfusta meydana gelen artışlar ve giderek artan sanayileşme doğrultusunda karbondioksit salınımı ve sera gazı etkisi artmaktadır. Bu doğrultuda küresel ısınma ve iklim değişikliğinin etkileri gün geçtikçe daha fazla görülmektedir. İncelenen istasyonlarda sıcaklıklarda artış trendi olduğu görülmektedir ve küresel ısınma ve iklim değişikliğinin etkileriyle bu artışların gelecek dönemlerde daha da fazla olacağı düşünülmektedir. Bu iller için yapılan çalışmanın, ileride yapılacak iklim değişikliği çalışmalarına, sıcaklıkların geçmiş dönemlerde göstermiş olduğu davranışla ilgili olarak fikir verebileceği düşünülmektedir.

\section{Çıkar Çatışması (Conflict of Interest)}

Yazarlar tarafından herhangi bir çıkar çatışması beyan edilmemiştir. No conflict of interest was declared by the authors.

\section{Kaynaklar (References)}

Ay, M., Özyıldırım, Y., 2017. Yozgat'ın Aylık Toplam Yağış ve Aylık Ortalama Hava Sıcaklıklarının Trend Analizi. Çukurova Üniversitesi Mühendislik-Mimarlık Fakültesi Dergisi, 32(2), 65-76.

Bayazit, M., Önöz, B., 2007. To Prewhiten or not to Prewhiten in Trend Analysis?. Hydrological Sciences Journal, 52(4), 611624.

Biberoğlu, E., 2011. Küresel İklim Değișikliğinin Türkiye Yağıș ve Sıcaklıkları Üzerindeki Etkilerinin Belirlenmesi. Yüksek Lisans Tezi, Dokuz Eylül Üniversitesi Fen Bilimleri Enstitüsü, İzmir.

Bolat, İ., Kara, Ö., Tok, E., 2017. Kastamonu, Karabük ve Bolu'da 1980-1999 ile 2000-2015 Yılları Arasındaki Sıcaklık ve Yağıșın Değișimi. Bartın Orman Fakültesi Dergisi, 19(1), 276-289.

Cebe, E. N., 2007. Türkiye Akarsularında Mevsimsel Trend Analizi. Yüksek Lisans Tezi, İstanbul Teknik Üniversitesi Fen Bilimleri Enstitüsü, İstanbul.

Coşkun, S., 2020. Van Gölü Kapalı Havzasında Yağışların Trend Analizi. Mühendislik Bilimleri ve Tasarım Dergisi, 8(2), 521532.

Çiflik, D., 2012. Ege Bölgesi DSİ İstasyonlarında Ölçülen Yıllık Toplam Yağışların Trend Analizi. Yüksek Lisans Tezi, Ege Üniversitesi Fen Bilimleri Enstitüsü, İzmir.

Doğan Demir, A., Demir, Y., Șahin, Ü., Meral, R., 2017. Bingöl İlinde Sıcaklık ve Yağıșların Trend Analizi ve Tarıma Etkisi. Türk Tarım ve Doğa Bilimleri Dergisi, 4(3), 284-291.

Ercan, B., Yüce, M. İ., 2018. Kilis İli Aylık Sıcaklık ve Yağış Verileri Trend Analizi. Dicle Üniversitesi Mühendislik Fakültesi Mühendislik Dergisi, 9(2), 947-953.

Kendall, M. G., 1948. Rank Correlation Methods.

Keskin, M., Çakto, İ., Çetin, V., Bektaș, O., 2018. Doğu Anadolu Bölgesi Sıcaklık ve Yağıș Trend Analizi. Mühendislik Bilimleri ve Tasarım Dergisi, 6(2), 294-300.

Kızılelma, Y., Çelik, M., Karabulut, M., 2015. İç Anadolu Bölgesinde Sıcaklık ve Yağışların Trend Analizi. Türk Coğrafya Dergisi, (64), 1-10.

Mann, H. B., 1945. Nonparametric Tests Against Trend. Econometrica: Journal of the econometric society, 245-259.

Oğuz, E., Oğuz, K., 2020. Şanlıurfa İli Yağıș ve Sıcaklık Trend Analizi. İklim Değișikliği ve Çevre, 5(1), 13-17.

Özfidaner, M., Şapolyo, D., Topaloğlu, F., 2018. Antalya Ortalama Sıcaklık Verisinde Gidișlerin Yeni Bir Gidiş Analiz Yöntemi ile Belirlenmesi. Ziraat Fakültesi Dergisi, 223-228.

Öztürk, Ö., Cebeci, İ., 2021. Büyük Menderes Havzasında Bazı Hidroklimatolojik Değişkenlerin Eğilim Analizi. Toprak Su Dergisi, 10(1), 43-50.

Özyıldırım, S., 2019. İç Anadolu Bölgesinde Sıcaklık ve Yağıș Değişkenlerinin Eğilim Analizi. Yüksek Lisans Tezi, Yozgat Bozok Üniversitesi Fen Bilimleri Enstitüsü, Yozgat.

Sen, P. K., 1968. Estimates of the Regression Coefficient Based on Kendall's Tau. Journal of the American Statistical Association, 63(324), 1379-1389.

Tabari, H., Talaee, P. H., 2011. Analysis of Trends in Temperature Data in arid and Semi-Arid Regions of Iran. Global and Planetary Change, 79(1-2), 1-10.

Tokgöz, S., Partal, T., 2020. Karadeniz Bölgesinde Yıllık Yağış ve Sıcaklık Verilerinin Yenilikçi Şen ve Mann-Kendall Yöntemleri ile Trend Analizi. Iğdır Üniversitesi Fen Bilimleri Enstitüsü Dergisi, 10(2), 1107-1118.

Türkeș, M., 2008. Küresel Iklim Değişikliği Nedir? Temel Kavramlar, Nedenleri, Gözlenen ve Öngörülen Değișiklikler. İklim Değişikliği ve Çevre, 1 (1), 26-37.

URL-1, https://cankiri.tarimorman.gov.tr/Link/38/Cankiri-Hakkinda (Erişim Tarihi: 20.04.2021).

URL-2, https://kastamonu.ktb.gov.tr/ (Erişim Tarihi: 21.04.2021).

Ülke, A., Özkoca, T., 2018. Sinop, Ordu ve Samsun İllerinin Sıcaklık Verilerinde Trend Analizi. Gümüşhane Üniversitesi Fen Bilimleri Enstitüsü Dergisi, 8(2), 455-463.

Yu, Y. S., Zou, S., Whittemore, D., 1993. Non-parametric Trend Analysis of Water Quality Data of Rivers in Kansas. Journal of Hydrology, 150(1), 61-80.

Yue, S., Pilon, P., Cavadias, G., 2002. Power of the Mann-Kendall and Spearman's Rho Tests for Detecting Monotonic Trends in Hydrological Series. Journal of Hydrology, 259(1-4), 254-271. 